\title{
Absorption of volatile fatty acids from the rumen of lactating dairy cows as influenced by volatile fatty acid concentration, $\mathrm{pH}$ and rumen liquid volume
}

\author{
BY JAN DIJKSTRA ${ }^{1}$, HUUG BOER ${ }^{1}$, JAAP VAN BRUCHEM ${ }^{2}$, \\ MARIANNE BRUINING ${ }^{1}$ AND SEERP TAMMINGA ${ }^{1}$ \\ ${ }^{1}$ Wageningen Agricultural University, Department of Animal Nutrition, Haagsteeg 4, 6708 PM \\ Wageningen, The Netherlands \\ ${ }^{2}$ Wageningen Agricultural University, Department of Human and Animal Physiology, Haarweg 10 , \\ 6709 PJ Wageningen, The Netherlands
}

(Received 10 September 1991-Accepted 25 March 1992)

\begin{abstract}
The effect of rumen liquid volume, $\mathrm{pH}$ and concentration of volatile fatty acids (VFA) on the rates of absorption of acetic, propionic and butyric acids from the rumen was examined in lactating dairy cows. Experimental solutions introduced into the emptied, washed rumen comprised two different volumes (10 or $30 \mathrm{l})$, four levels of $\mathrm{pH}(4 \cdot 5,5 \cdot 4,6 \cdot 3,7 \cdot 2)$ and three levels of individual VFA concentrations $(20,50$ or $100 \mathrm{~mm}$-acetic, propionic or butyric acid). All solutions contained a total of $170 \mathrm{mM}-\mathrm{VFA}$ and an osmotic value of $400 \mathrm{mOsmol} / \mathrm{l}$. Absorption rates were calculated from the disappearance of VFA from the rumen corrected for passage with liquid phase to the omasum. An increase in initial fluid pH caused a reduction in fractional absorption rates of propionic and butyric acids. Increasing the initial $\mathrm{pH}$ from 4.5 to 7.2 reduced fractional absorption rates of acetic, propionic and butyric acids from 0.35, 0.67 and 0.85 to $0.21,0.35$ and $0.28 / \mathrm{h}$ respectively. The fractional absorption rates of all VFA were reduced $(P<0.05)$ by an increase in initial rumen volume. The fractional absorption rate of acetic acid was lower $(P<0.05)$ at an initial concentration of $20 \mathrm{~mm}$ than of $50 \mathrm{~mm}$. The fractional absorption rate of propionic acid tended $(P<0.10)$ to decrease as the level of concentration increased while fractional absorption rate of butyric acid was not affected by butyric acid concentration. These results indicate that relative concentrations of VFA in rumen fluid might not represent relative production rates and that attempts to estimate individual VFA production from substrate digestion must take account of $\mathrm{pH}$ and VFA concentration.
\end{abstract}

Volatile fatty acids: Dairy cows

In the rumen of dairy cows volatile fatty acids (VFA) are produced by microbial fermentation of carbohydrates and protein. Acetic, propionic and butyric acids are the predominant VFA occurring in the rumen fluid, their concentration and relative proportions related to the level of feed intake (Sutton, 1985) and the composition of the diet (Murphy et al. 1982). In ruminants VFA constitute the major source of energy, providing at least $50 \%$ of the total amount of digested energy (Sutton, 1985). Both the yield of total VFA and the type of VFA formed can significantly affect the utilization of absorbed nutrients in dairy cows and, thus, can affect milk volume and composition to a considerable extent (Thomas \& Martin, 1988).

Various methods have been applied to estimate or predict the amount of individual VFA available from rumen fermentation. Production rates of VFA as measured by isotopedilution techniques showed a wide variability and errors of measurement have been discussed (Sutton, 1985). Due to metabolism of VFA by the rumen mucosa, estimates of 
VFA availability by measurement of the amounts of VFA appearing in the portal system are considerably lower than those measured by the previous method, and the applicability of the results has been questioned (Bergman, 1990). A third approach is to estimate the amount of available VFA by prediction from the amount of substrate fermented in the rumen, multiplied by stoichiometric fermentation variables for these substrates (Koong et al. 1975; Black et al. 1981; Murphy et al. 1982). The accuracy of this approach depends, amongst other aspects, on the relationship between VFA production and VFA concentration in the rumen fluid, so quantitative information on the rate of absorption of individual VFA from the rumen is required. Several experiments have been performed to study this rate of VFA absorption. The effects of chain length, $\mathrm{pH}$, effective absorptive surface area, osmolality and concentration on individual VFA absorption rates have been reported (for reviews, see Bugaut, 1987; Bergman, 1990). However, results are conflicting, probably because of differences in experimental methods applied (Carter \& Grovum, 1990). In particular, in vitro studies give qualitative rather than quantitative results and results are often not applicable to the normal functioning animal (Bergman, 1990). Also, the vast majority of these experiments have been performed with sheep and between-species differences in rates of absorption might exist (Bugaut, 1987).

The objective of the present study was to quantify the effects of rumen liquid volume, $\mathrm{pH}$ and concentration of VFA on the fractional rates of absorption of acetic, propionic and butyric acids from the rumen of lactating dairy cows.

\section{MATERIAL AND METHODS}

\section{Animals and diets}

Two 7-year-old lactating Black and White cows (crossbred Friesian/Holstein-Friesian) fitted with large rumen cannulas (Bar Diamond, Idaho, USA) were used. The cows were 2-3 months in lactation at the start of the experiment. The average milk production of the cows during the experimental period ( 2 months) was $16.5 \mathrm{~kg} / \mathrm{d}$. Cows grazed together with the other cows in the herd, and in addition received $2 \mathrm{~kg}$ commercial concentrate during the experimental period.

\section{Experimental design and procedures}

A total of twelve experimental solutions were prepared containing three levels of individual VFA concentration (20,50 or $100 \mathrm{~mm}$-acetic, propionic or butyric acid) and four levels of $\mathrm{pH}(4.5,5 \cdot 4,6 \cdot 3$ or $7 \cdot 2)$ which were introduced to the rumen at two different volumes (10 or 301 ). The solutions were based on McDougall's (1948) buffer and the composition of the solutions is given in Table 1 . All solutions contained $170 \mathrm{~mm}-\mathrm{VFA}$. The $\mathrm{pH}$ of the solutions was set at the desired level by addition of $\mathrm{NaOH}$ or $\mathrm{HCl}$ and if necessary $\mathrm{NaCl}$ was added to give an osmolality of approximately $400 \mathrm{mOsmol} / \mathrm{l}$. Fractional outflow rate of rumen fluid was estimated utilizing CoEDTA as a marker (70 $\mathrm{mg}$ CoEDTA $(140 \mathrm{~g} / \mathrm{kg}) / 1$; Uden et al. 1980).

During the experimental period ( 2 months) the cows were confined in a stall after the morning milking every Monday, Wednesday and Friday. Rumen ingesta were removed and stored in an insulated container before return. Once the rumen had been washed four times with warm water, it was washed twice more with 5 litres of the experimental solution at body temperature. Next, either 10 or 30 litres of the solution were introduced to the rumen and left for $60 \mathrm{~min}$. Samples were taken immediately and every $10 \mathrm{~min}$ after introduction of the solution for determination of $\mathrm{pH}$, osmolality and concentration of Co and VFA of rumen fluid. After $60 \mathrm{~min}$ the fluid was removed and the withdrawn volume measured. Each combination of $\mathrm{pH}(n 4)$, VFA concentration $(n 3)$ and volume $(n 2)$ of the solution 
Table 1. Composition of the experimental solutions

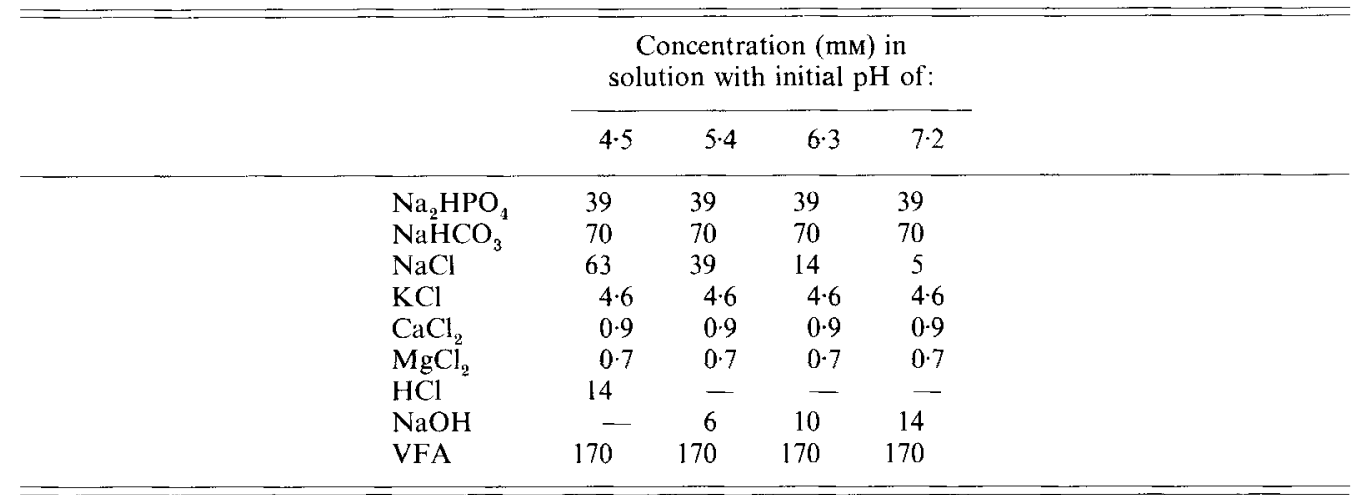

Concentration of acetic, propionic and butyric acids in solutions 1,2 and 3 respectively: 100, 50, 20 mm; 20, $100,50 \mathrm{~mm} ; 50,20,100 \mathrm{~mm}$.

VFA, volatile fatty acids.

was assigned randomly to one of the days. However, in the pre-experimental period it was shown that the $\mathrm{pH}$ of the solutions increased rapidly after introduction to the rumen. Hence in the experimental design, six of the twelve solutions with a $\mathrm{pH}$ of 6.3 or 7.2 were replaced by solutions with a $\mathrm{pH}$ of 4.5 or 5.4 .

In all samples $\mathrm{pH}$ was measured immediately after collection. Fluid osmolality was determined within $3 \mathrm{~h}$ after collection by freezing-point depression (Knauer half microosmometer) in a portion of the samples taken at 0 and 60 min after introduction of the solution. Co concentration was determined in another portion of these samples using an atomic absorption spectrophotometer (Varian Spectra-300). A portion (10 ml) of the samples was acidified with $0.5 \mathrm{ml}$ phosphoric acid $(850 \mathrm{ml} / 1)$ and frozen at $-15^{\circ}$ until analysed for VFA concentrations by gas-liquid chromatography (Packard Becker, model 419 , glass column filled with chromosorb 101 , carrier gas $\left(\mathrm{N}_{2}\right)$ saturated with formic acid at approximately $190^{\circ}$, isovaleric acid was used as the internal standard).

\section{Calculation of results and statistical analysis}

The water inflow, fractional outflow rate of fluid, and fractional absorption rates of acetic, propionic and butyric acids were calculated using the differential equations:

$$
\begin{aligned}
d \mathrm{Co} / d t & =-k_{1} \mathrm{Co}, \\
d V / d t & =-k_{1} V+I, \\
d \mathrm{VFA} / d t & =-\left(k_{1}+k_{r}\right) \mathrm{VFA},
\end{aligned}
$$

where $\mathrm{Co}$ is the amount of cobalt in the rumen $(\mathrm{g}) ; V$ is rumen fluid volume $(1) ; I$ is constant inflow of water to the rumen $(1 / \mathrm{h})$; VFA is amount of acetic, propionic or butyric acid in the rumen $(\mathrm{mmol}) ; k_{1}$ is fractional liquid passage rate $(/ \mathrm{h}) ; k_{r}$ is fractional absorption rate of VFA $(/ \mathrm{h}) ; t$ is time $(\mathrm{h})$. The analytical solutions to equations $1-3$ are as follows:

$$
\begin{aligned}
\mathrm{Co} & =\operatorname{Co}(0) \exp \left(-k_{1} t\right), \\
V & =\left(V(0)-I / k_{1}\right) \exp \left(-k_{1} t\right)+I / k_{1}, \\
\mathrm{VFA} & =\operatorname{VFA}(0) \exp \left[-\left(k_{1}+k_{r}\right) t\right],
\end{aligned}
$$


where $\operatorname{Co}(0), V(0)$ and $\operatorname{VFA}(0)$ denote the amount of $\mathrm{Co}$, and the volume and the amount of VFA respectively, immediately after introduction of the solution to the rumen. Since the initial and the end values of Co, $V$ and VFA have been determined, the inflow of water, fractional passage and absorption rates can be calculated.

Data were subjected to least squares analysis of variance by the general linear model procedure (SAS Institute Inc., 1985), with results expressed as least square means, using the general model:

$$
y_{i j k l}=\mu+A_{i}+P_{j}+V_{k}+S_{l}+e_{i j k l},
$$

where $\mu$ is the overall mean, $A_{i}, P_{j}, V_{k}$ and $S_{l}$ are the animal, $\mathrm{pH}$, volume and solution composition effect respectively, and $e_{i j k l}$ is the residual term. Effect of day of introduction of experimental solutions was detected $(P<0.05)$ only for the initial and end osmolality of rumen fluid using the procedures as described by Gill \& Hafs (1971), and after examination of uniformity of correlations between data for any $2 \mathrm{~d}$ was dropped for all the other variables. Of all possible interaction terms amongst treatments, a volume $\times \mathrm{pH}$ interaction was detected $(P<0.05)$ only for the end $\mathrm{pH}$ of rumen fluid and, hence, for all other variables, interactions were not included in the analysis. Means were separated using the Tukey test.

Finally, a non-linear equation was fitted by the non-linear regression procedure (SAS Institute Inc., 1985) to the data corrected for dilution and outflow of VFA with the fluid, to estimate the amount of each VFA absorbed in relation to the $\mathrm{pH}$, concentration and volume :

$$
T=v_{m} V^{0.75} /\left[\left(1+\left(K / \mathrm{C}_{\mathrm{VFA}}\right)^{\Phi}\right)\left(1+(\mathrm{pH} / J)^{\Theta}\right)\right],
$$

where $T$ is the amount of each VFA absorbed per unit time $(\mathrm{mmol} / \mathrm{h}) ; v_{m}$ is maximum absorption rate (mmol/1 per $h$ ); $V^{0.75}$ is metabolic volume of the rumen, representing the absorptive surface (1);K is affinity constant for absorption of VFA $(\mathrm{mmol} / \mathrm{l}) ; \mathrm{C}_{\mathrm{VFA}}$ is concentration of VFA in rumen fluid (mmol/l); $J$ is inhibition constant for absorption of VFA related to $\mathrm{pH}$ of rumen fluid; $\Theta, \Phi$ are sigmoidal steepness variables. This equation was formulated based on two assumptions. First, at high rumen concentrations absorption can be limited as the VFA accumulate within the receiving cell or if the availability of ions for co- or countertransport is limiting, while low concentrations will limit absorption as the concentration gradient decreases. Both can be represented simultaneously sigmoidally in the first part of the denominator (Thornley \& Johnson, 1990). Second, since the absorption of dissociated VFA is negligible, $\mathrm{pH}$ will affect absorption rates by affecting the dissociated: undissociated VFA ratio according to the Henderson-Hasselbalch equation. This is represented in the second part of the denominator.

\section{RESULTS}

Values in Table 2 refer to the rumen fluid indices as affected by initial $\mathrm{pH}$, composition and volume of the experimental solution. The fractional fluid passage rate was not affected by $\mathrm{pH}$ or volume, but the composition of the solution had a tendency $(P<0 \cdot 10)$ to affect the outflow rate. For all treatments there was a net inflow of water to the rumen. With increasing levels of initial $\mathrm{pH}$ the net fluid inflow tended to increase. Similarly, the net fluid inflow was significantly higher $(P<0.05)$ with the higher initial volume. The fluid end volume is a result of the initial volume, passage rate and inflow of water. Thus, both initial volume $(P<0.01)$ and $\mathrm{pH}(P<0.05)$ significantly affected the fluid end volume. After $1 \mathrm{~h}$ rumen fluid $\mathrm{pH}$ reached an end value of $8 \cdot 0-8 \cdot 2$, except for the solutions with an initial value of $\mathrm{pH} 4.5$. The end $\mathrm{pH}$ was significantly lower $(P<0.05)$ for the higher initial liquid volume. Average initial fluid osmolality was $392 \mathrm{mOsmol} / 1$ and was not related $(P>0 \cdot 10)$ 

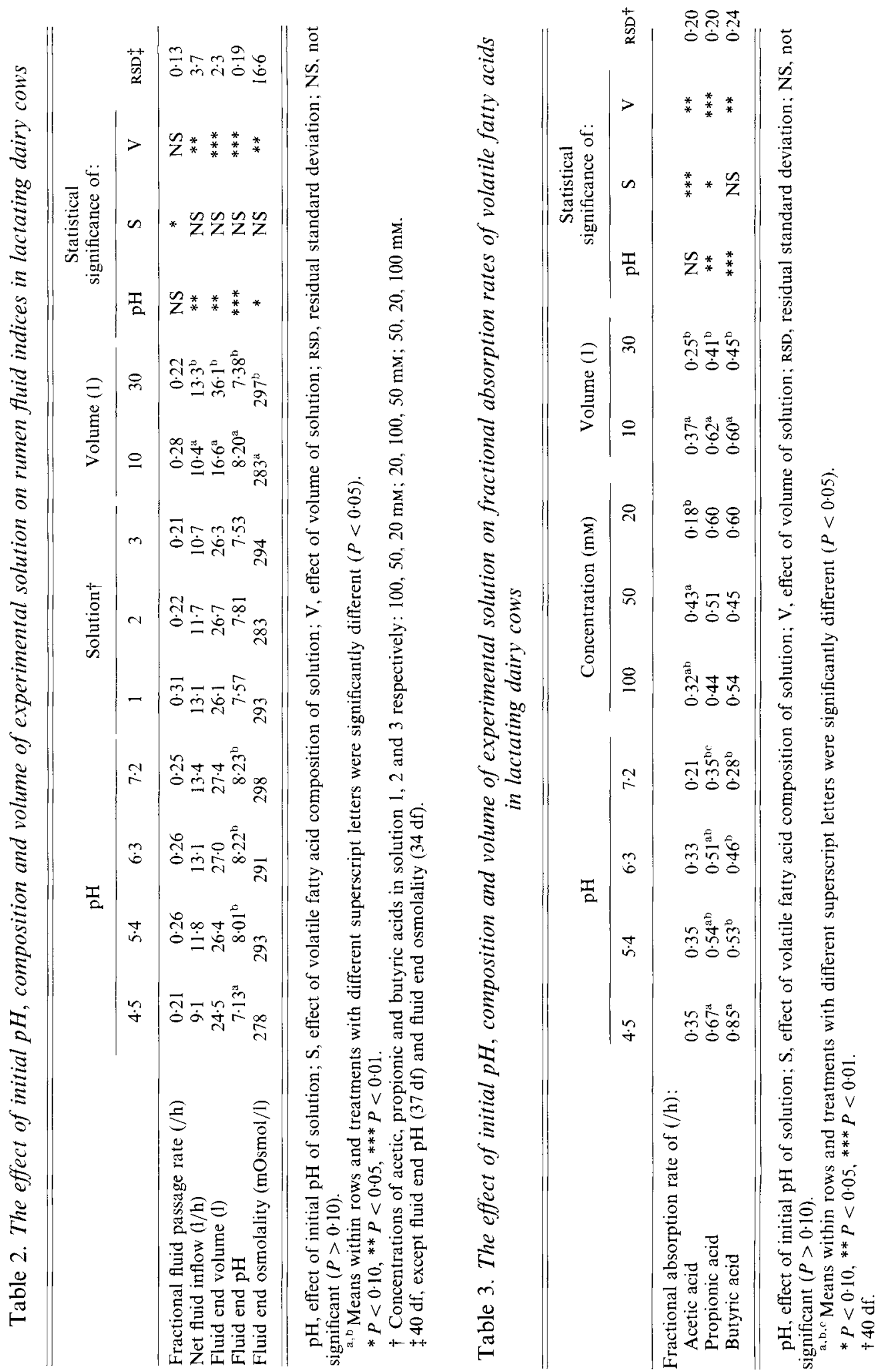


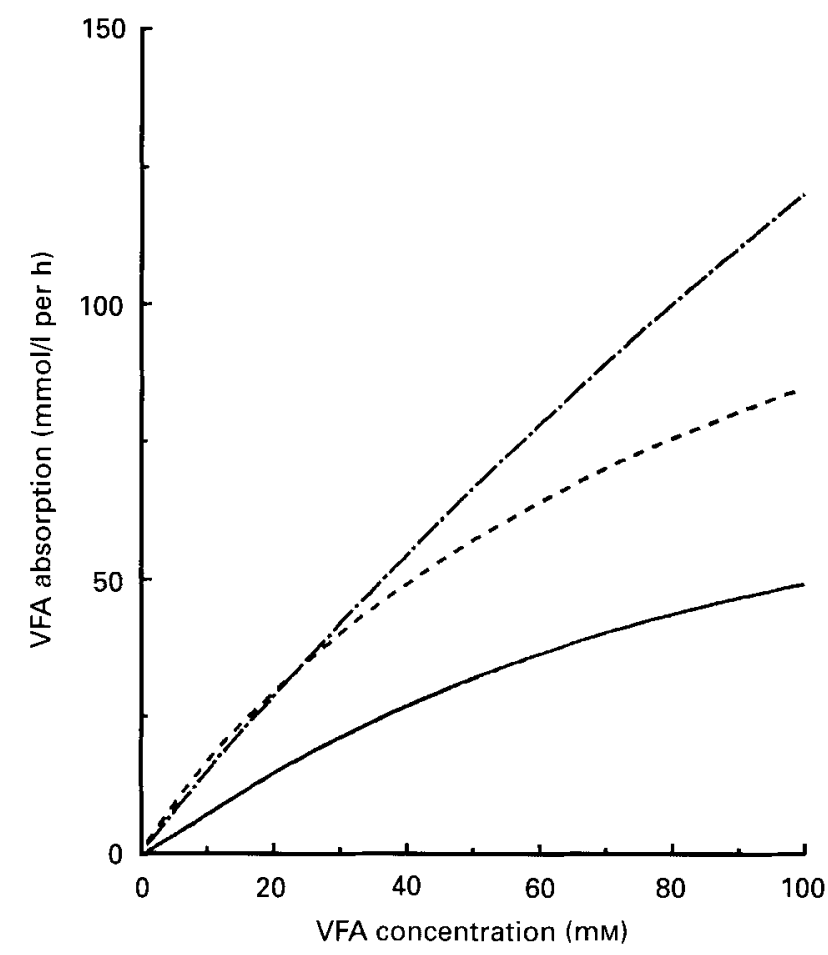

Fig. 1. Infuence of concentration of acetic, propionic or butyric acid on the absorption of acetic ( - ), propionic $\left(---_{--)}\right.$and butyric $\left(-+^{-}\right)$) acids at $\mathrm{pH}$ of 6.0 for lactating dairy cows calculated from equation 8 : $T=v_{n t} V^{0 \cdot 75} /\left[\left(1+\left(K / \mathrm{C}_{\mathrm{ve} \lambda}\right)^{\Phi}\right)\left(1+(\mathrm{pH} / J)^{\Theta}\right)\right]$, where $T$ is the amount of each volatile fatty acid (VFA) absorbed per unit time $(\mathrm{mmol} / \mathrm{h}) ; v_{m}$ is maximum absorption rate $(\mathrm{mmol} / \mathrm{l}$ per $\mathrm{h}) ; V^{0.75}$ is metabolic volume of the rumen, representing the absorptive surface (1); $K$ is affinity constant for absorption of VFA (mmol/l); $\mathrm{C}_{\mathrm{VFA}}$ is concentration of VFA in rumen fluid $(\mathrm{mmol} / \mathrm{l}) ; J$ is inhibition constant for absorption of VFA related to $\mathrm{pH}$ of rumen fluid; $\Theta, \Phi$ are sigmoidal steepness variables.

\begin{tabular}{lccccccc}
\multicolumn{1}{c}{ VFA } & $v_{m}$ & $K$ & $J$ & $\Phi$ & $\Theta$ & $R^{2}$ & RSD \\
Acetic acid & $172 \cdot 0$ & $79 \cdot 1$ & 6.02 & $1 \cdot 17$ & 3.91 & 0.74 & 18.9 \\
Propionic acid & $356 \cdot 2$ & 112.0 & 6.02 & 0.95 & 4.61 & 0.82 & 20.3 \\
Butyric acid & 1391.2 & 493.4 & 6.02 & 0.99 & 5.13 & 0.89 & 18.2
\end{tabular}

where $R^{2}$ is coefficient of determination and RSD is residual standard deviation. For details of equation 8 , see p. 388 .

to either initial $\mathrm{pH}$, volume or composition of the solution. After $60 \mathrm{~min}$ fluid osmolality was decreased to an average $288 \mathrm{mOsmol} / 1$. Low levels of both initial $\mathrm{pH}$ and volume resulted in low osmolality values. Again, there was no effect $(P>0 \cdot 10)$ of composition of the solution.

Fractional absorption rates of acetic, propionic and butyric acids, as influenced by initial $\mathrm{pH}$, composition and volume of the experimental solution, are given in Table 3 . Fractional absorption rates of propionic and butyric acids were significantly $(P<0.05)$ higher with low initial $\mathrm{pH}$ levels, but the fractional absorption rate of acetic acid was not significantly $(P>0 \cdot 10)$ affected by initial $\mathrm{pH}$, although the estimated absorption rate tended to decrease with an increase in $\mathrm{pH}$. Fractional absorption rates of acetic, propionic and butyric acids were compared (Tukey test) within initial $\mathrm{pH}$ levels using the pooled average standard deviation (Snedecor \& Cochran, 1967). Fractional absorption rates of the VFA with an initial $\mathrm{pH}$ of 4.5 were, in order $(P<0.05)$ : butyric acid $>$ propionic acid $>$ acetic acid; with 


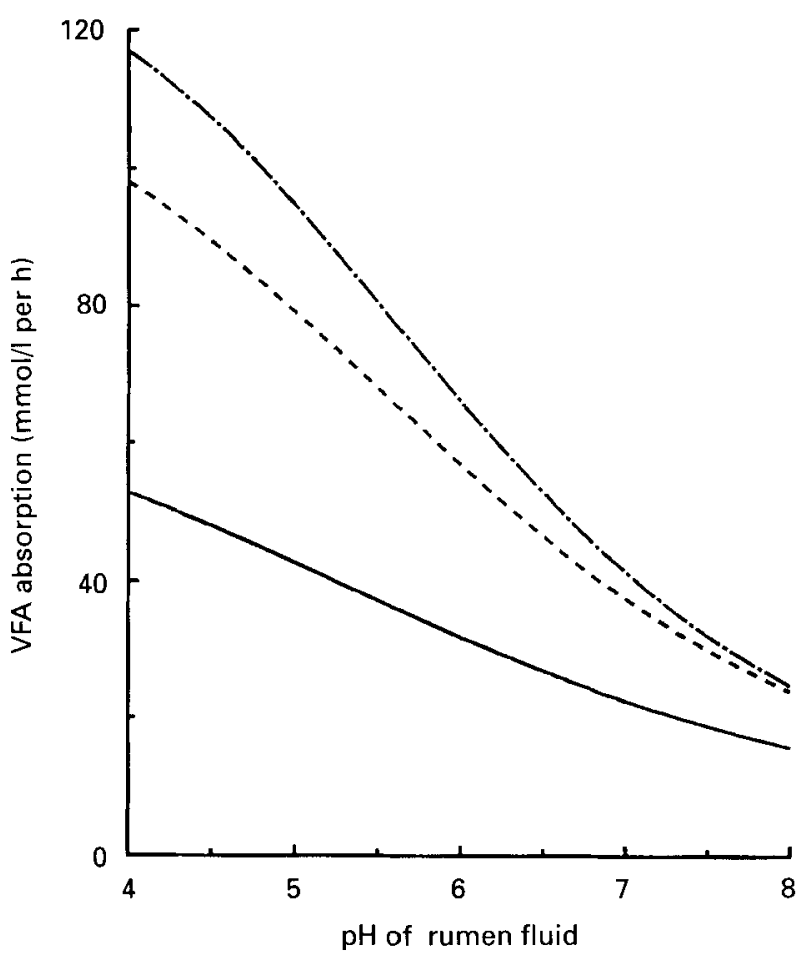

Fig. 2. Influence of $\mathrm{pH}$ of rumen fluid on absorption of acetic $(--)$, propionic (--.----) and butyric (-- - - ) acids at a concentration of each acid of $50 \mathrm{~mm}$ for lactating dairy cows. The variables of the equations are given in Fig. 1 .

an initial $\mathrm{pH}$ of $5 \cdot 4$, this order was butyric acid = propionic acid $>$ acetic acid; and with initial $\mathrm{pH}$ values of 6.3 and 7.2 no significant $(P>0.05)$ differences between absorption rates of the VFA were detected. The composition of the solution had a significant $(P<$ $0.01)$ effect on the fractional absorption rate of acetic acid, the intermediate level of concentration $(50 \mathrm{~mm})$ being significantly higher than the low level of concentration $(20 \mathrm{~mm})$. Fractional absorption rate of propionic acid tended $(P<0 \cdot 10)$ to increase with decreasing concentrations of propionic acid in the solution, but fractional absorption rate of butyric acid was not significantly $(P>0 \cdot 10)$ affected by the concentration of the acid. For all VFA, fractional absorption rates were significantly $(P<0.05)$ higher with the 10 litre solution than the 30 litre solution.

The effects of concentration and $\mathrm{pH}$ on the amount of each VFA absorbed are illustrated in Figs. 1 and 2. In Fig. 1 the amount of VFA absorbed as estimated by equation 8 at $\mathrm{pH}$ 6.0 is presented; in Fig. 2 the estimated amount of VFA absorbed at concentration $50 \mathrm{~mm}$ is presented. The estimates of the variables suggest a higher potential maximum absorption rate for butyric acid than the other acids, and a higher potential maximum absorption rate for propionic acid than acetic acid. The individual $\mathrm{pH}$ values for half-maximum speed $(J$ in equation 8) were very close to each other and a constraint on the estimation of this variable was added to ensure the same value for each VFA. The estimate of this variable was $6 \cdot 0$. The sigmoidal steepness variable for the concentration effect $(\Phi)$ significantly reduced the residual variation for acetic acid only, indicating a weak sigmoid behaviour for this acid. The absorption of VFA showed a more pronounced sigmoidal behaviour in response to changes of the $\mathrm{pH}$ of the rumen fluid, the steepness variable $(\Theta)$ being highest 
for butyric and lowest for acetic acid. Hence, with a decrease in $\mathrm{pH}$, absorption of butyric acid will increase more than the other acids and absorption of propionic acid more than acetic acid.

\section{DISCUSSION}

In previous studies VFA absorption rates have been examined in vitro or using animals in which the reticulo-rumen has been isolated by ligatures, using rumen pouches or resorption chambers. Though allowing precise control and accurate measurements to elucidate mechanisms of absorption, results of these studies are not directly applicable to the normal lactating dairy cow (Stevens, 1970; Bergman, 1990). The present study used intact, lactating dairy cows to allow estimations of VFA absorption rates which would be generally applicable to dairy cattle.

\section{Fluid dynamics and osmolality of fuid}

Clearance of VFA from the rumen is either by passage with the fluid to the omasum, or by absorption through the rumen wall. For this reason it is important to quantify the rumen fluid dynamics related to the $\mathrm{pH}$, composition and volume of solutions introduced to the rumen. In a recent review Carter \& Grovum (1990) suggested that the mechanisms governing the movements of water to and from the rumen operate to minimize insults to the osmotic balance between rumen and body fluids, with a significant amount of water inflow determined at osmolality values higher than $370 \mathrm{mOsmol} / 1$. Indeed, in the present study the net water inflow appeared to be related to the osmotic pressure of the rumen fluid, giving rise to differences in end volume of the rumen fluid since the fractional liquid passage rate was not affected by $\mathrm{pH}$, composition or volume of the experimental solution. The VFA are major determinants of rumen fluid osmotic pressure, both directly and by co- or countertransport of other ions. Absorption of VFA has been shown to be linked to $\mathrm{HCO}_{3}{ }^{-}$ secretion into the rumen fluid in the ratio 2:1 (Masson \& Phillipson, 1951; Ash \& Dobson, 1963; Gäbel et al. 1989). Hence, increments in fractional absorption rates of VFA due to decreases in $\mathrm{pH}$ or in rumen volume (Table 3) will result in a decrease of the rumen fluid osmotic pressure (Table 2). Both the absorption of VFA into rumen epithelial cells and the concomitant secretion of $\mathrm{HCO}_{3}^{-}$will contribute to the increase in $\mathrm{pH}$ and explain the observed lower end $\mathrm{pH}$ at the higher volume level. From a summary of several studies Warner \& Stacy (1972) showed that a zero net flux of water across the rumen wall occurred at osmolality values in the range of $295-360 \mathrm{mOsmol} / \mathrm{l}$. Considering the relationship between osmotic pressure and fluid dynamics it might be suggested that the relative net water flux decreased with time after introduction of the solution, since the osmotic pressure decreased from an initial value of approximately $400 \mathrm{mOsmol} / 1$ to an end value of $290 \mathrm{mOsmol} / 1$. Before $1 \mathrm{~h}$ was over water inflow may have become negative. However, in the calculations a constant inflow of water during the hour was assumed. Hence, VFA absorption rates may have been overestimated in the first period after introduction and underestimated in the later period. However, saliva also contributes to water inflow and it was observed that animals were salivating from the moment of introduction until removal of the solution. Equally, high osmotic values of rumen fluid have been shown to decrease VFA fractional absorption rates (Oshio \& Tahata, 1984) and, conceivably, this effect of osmotic pressure might balance to some extent the effect of assuming a constant water inflow on absorption rates.

\section{$V F A$ absorption}

In a number of studies the effects of $\mathrm{pH}$ and osmolality of fluid, effective surface area, type and concentration of VFA on absorption of VFA have been reported (for reviews, see Bugaut, 1987; Bergman, 1990). Based on these results several models of VFA absorption 
have been proposed (Ash \& Dobson, 1963; Stevens, 1970; Argenzio, 1988; Gäbel, 1990). In these models VFA absorption is explained to a large extent by diffusion, the rate affected by $\mathrm{pH}$ of the fluid at the lumen side, cell contents and intracellular metabolism of VFA. Except for the Stevens (1970) model, all models assume transport systems across the rumen epithelium supplying protons for the conversion of a VFA anion to the acid form. The present study gives considerable support to the model of VFA-coupled exchange of protons. Ionized components do not diffuse passively across the rumen cell membrane (Bugaut, 1987; Gäbel, 1990). Yet even at $\mathrm{pH}$ levels above neutral ( $\mathrm{pH} 7.0)$ and, hence, according to the Henderson-Hasselbalch equation, more than $99 \%$ of each VFA present is in the dissociated form, substantial VFA fractional absorption rates were calculated (Table 3). Moreover, the estimated $\mathrm{pH}$ value for half-maximum rate of VFA absorption was 6.0 (Fig. 1) and at this pH value only $6 \%$ of each VFA is present in the dissociated form. It is obvious that protons have been supplied to the dissociated VFA to establish such relatively high fractional absorption rates, probably in an acid microclimate near the rumen wall (Bugaut, 1987). Both the present study and the work reported by Danielli et al. (1945), Tsuda (1956), Aafjes (1967), Weigand et al. (1972), Thorlacius \& Lodge (1973) and MacLeod \& Ørskov (1984) found decreasing $\mathrm{pH}$ levels to increase fractional absorption rates. Furthermore, the present study showed that increased fractional absorption rates were significantly affected by the type of VFA absorbed (Table 3 ). Similar $\mathrm{pH} \times$ type of VFA interactions on clearance of VFA have been reported by a number of authors (Danielli et al. 1945; Pfander \& Phillipson, 1953; Tsuda, 1956; Hogan, 1961; Aafjes, 1967; Weigand et al. 1972; Thorlacius \& Lodge, 1973; Oshio \& Tahata, 1984), indicating that at alkaline $\mathrm{pH}$ levels relative rates of absorption of the three VFA do not differ to such a great extent as at acid $\mathrm{pH}$ levels.

Several authors reported the absorption of the major VFA as a direct relationship to their rumen concentration (Masson \& Phillipson, 1951; Tsuda, 1956; Hogan, 1961; Weigand et al. 1972; Thorlacius \& Lodge, 1973; Oshio \& Tahata, 1984), although the absorption of valeric acid decreased as rumen fluid concentration of valeric acid increased (Oshio \& Tahata, 1984). In contrast, in the present study the fractional absorption rate of acetic acid was decreased at the lowest concentration level $(20 \mathrm{~mm})$ and also tended to decrease at the highest concentration level $(100 \mathrm{~mm})$. The fractional absorption rate of propionic acid tended to decrease with an increase in the concentration. In attempting to reconcile this result one must remember first, that absorption of VFA is a diffusion process and the rate is dependent on, amongst others, the concentration gradient, and second, that propionic and butyric acids are extensively metabolized by the rumen epithelial tissue. The latter mechanism is reflected in the relatively low levels of propionic and butyric acids in the portal blood of ruminants (Bergman, 1990). Thus, the low rumen acetic acid concentration achieved with an initial concentration of $20 \mathrm{~mm}$ (the minimum values observed were $6 \mathrm{~mm}$ ) and the relatively high concentration of acetic acid in the blood will result in a rather low concentration gradient and, hence, decrease the fractional absorption rate. As the capacity of the epithelial cell for VFA can be saturated (Bergman, 1990), at high levels of propionic acid in the rumen fluid the metabolism of this acid in the cell might contribute less to the clearance of propionic acid from the rumen, decreasing the fractional absorption rate. However, the reason for butyric acid fractional absorption rate not being affected by the concentration is not apparent. It should be noted also that both the lowest acetic acid concentration and the highest propionic and butyric acid concentrations are outside the normal physiological range measured in rumen fluid of dairy cattle.

As well as the previously mentioned factors, the quantity of VFA absorbed from the rumen depends on the effective surface area (Dobson, 1984; Bugaut, 1987). However, none of the reports on VFA absorption from the rumen studied the effect of the liquid volume 
on clearance rates. In the present study absorption rates were significantly affected by the volume of the experimental solution introduced. Since an increase in liquid volume is expected to increase the average distance of a solute from the rumen mucosa and hence decrease the diffusion rate, the influence of the absorptive epithelium can be inferred from these findings. The present results indicate that the effect of volume and surface area could be represented by metabolic volume (volume ${ }^{0.75}$ ). This was confirmed by analysis of the experimental data using equation 8 , in which the 0.75 term was replaced by an independent variable. The estimation of this independent variable was 0.69 . The absorptive surface in relation to the liquid volume will have an effect on the pathway (absorption across the rumen wall or passage to the omasum) of VFA disappearance from the rumen as well. In sheep (Sutherland, 1963; Von Engelhardt \& Hauffe, 1975) and calves (Edrise \& Smith, 1977) the estimated contribution of passage was $10-20 \%$ of the total disappearance from the rumen. In cattle this value was estimated to be $30 \%$ at maintenance level and $40 \%$ at four times maintenance (Tamminga \& Van Vuuren, 1988). Although differences in $\mathrm{pH}$ and fractional passage rates could explain some of these species and intake level differences on the contribution of passage to VFA clearance, it is clear that the generally higher liquid volume in cattle contributes substantially to an explanation of these differences since, unlike absorption, passage of VFA to the omasum is assumed to increase linearly with an increase in the total amount of VFA present in the rumen. In turn, at a higher rumen liquid volume, this relatively reduced clearance rate of VFA per unit volume might reduce rumen capacity and $a d$ lib. feed intake (Tamminga \& Van Vuuren, 1988). By extrapolation from the volumes used in the present experiment (10 or 301$)$, using equation 8 , to the volumes in the previously described report (55-80 1, Tamminga \& Van Vuuren, 1988), the estimated contribution of passage to VFA disappearance was in the range of $20-35 \%$, slightly less than estimated by Tamminga \& Van Vuuren (1988).

The quantitative results of the present study are not readily comparable to other studies of VFA absorption. First, results reported in the literature show a wide range of variation due to differences in the experimental methods applied (Carter \& Grovum, 1990; Bergman, 1990). Second, the present study found significant effects of $\mathrm{pH}$, concentration, volume and type of VFA on rate of absorption from the rumen. Previous studies, however, have seldom reported the volume of the fluid in the experiment, or have reported absorption rates using individual VFA concentrations which are often within the range usually found in rumen fluid, or have used solutions with interrelated $\mathrm{pH}$ and VFA concentration levels. Clearly, the present study indicates that mathematical models of rumen fermentation which are developed to predict nutrient supply to the animal should consider the volume, concentration, $\mathrm{pH}$ and type of VFA in order to predict accurately the dynamics of VFA absorption. Equally, results of the present study suggest that the often reported relative concentrations of VFA in the rumen fluid might not represent the relative production rates, particularly at acid pH levels. From a summary of published values Sutton (1985) concluded that the agreement between molar proportions of VFA produced, as measured by isotope-dilution methods, and molar proportions found in the rumen fluid was less variable for high-roughage diets than high-concentrate diets and less variable for sheep than cattle. The different effects of $\mathrm{pH}$ on the absorption of VFA in the present study add to an explanation of this variation, as high-concentrate diets support relatively low $\mathrm{pH}$ values of rumen fluid and, generally, the $\mathrm{pH}$ of rumen fluid in cattle is lower than in sheep. In this regard, unlike recent studies (Koong et al. 1975; Black et al. 1981; Murphy et al. 1982), $\mathrm{pH}$ of the rumen fluid and the concentration of each VFA have to be included if predictions of VFA production from substrate digestion in the rumen and VFA molar proportions are to be accurate. 
The authors gratefully acknowledge Miss Monique Daniels and Miss Susan Van den Hoven who contributed as undergraduate students to the experiment described in the present paper, and Mrs Toos Lammers-Wienhoven and $\mathrm{Mr}$ Theo Viets for skilled analytical assistance.

\section{REFERENCES}

Aafjes, J.H. (1967). The disappearance of volatile fatty acids through the rumen wall. Zeitschrift für Tierphysiologie. Tierernährung und Futtermittelkunde 22, 69-75.

Argenzio, R. A. (1988). Fluid and ion transport in the large intestine. In Aspects of Digestive Physiology in Ruminants, pp. 140-155 [A. Dobson and M. J. Dobson, editors]. Ithaca: Comstock Publishing Associates.

Ash, R. W. \& Dobson, A. (1963). The effect of absorption on the acidity of rumen contents. Journal of Physiology 169, 39-61.

Bergman, E. N. (1990). Energy contributions of volatile fatty acids from the gastrointestinal tract in various species. Physiological Reviews 70, 567-590.

Black, J. L., Beever, D. E., Faichney, G. J., Howarth, B. R. \& Graham, N. McC. (1981). Simulation of the effects of rumen function on the flow of nutrients from the stomach of sheep: part 1 - description of a computer program. Agricultural Systems 6, 195-219.

Bugaut, M. (1987). Occurrence, absorption and metabolism of short chain fatty acids in the digestive tract of mammals. Comparative Biochemistry and Physiology 86B, 439-472.

Carter, R. R. \& Grovum, W. L. (1990). A review of the physiological significance of hypertonic body fiuids on feed intake and ruminal function: salivation, motility and microbes. Joumal of Animal Science 68, $2811-2832$.

Danielli, J. F., Hitchcock, M. W. S., Marshall, R. A. \& Phillipson, A. T. (1945). The mechanisms of absorption from the rumen as exemplified by the behaviour of acetic, propionic and butyric acids. Journal of Experimental Biology 22, 75-84.

Dobson, A. (1984). Blood flow and absorption from the rumen. Quarterly Journal of Experimental Physiology 69 , 599-606.

Edrise, B. M. \& Smith, R. H. (1977). Absorption of volatile fatty acids in different compartments of the ruminant stomach. Proceedings of the Nutrition Society 36, 149A.

Gäbel, G. (1990). Pansenazidose: Interaktionen zwischen den Veränderungen im Lumen und in der Wand des Pansens (Acidosis: Interrelations between changes in the lumen and the wall of the rumen). Übersichten Tierernährung 18, 1-38.

Gäbel, G., Bestmann, M. \& Martens, H. (1989). Bikarbonattransport im Pansen; Einfluß der Diät und von kurzkettigen Fettsäuren und Chlorid (Bicarbonate transport in the rumen; effects of diet and of short chain fatty acids and chloride). Journal of Animal Physiology and Animal Nutrition 62, 20-21.

Gill, J. L. \& Hafs, H. D. (1971). Analysis of repeated measurements of animals. Journal of Animal Science 33, $331-336$

Hogan, J. P. (1961). The absorption of ammonia through the rumen of sheep. Australian Journal of Biological Science 14, 448-460.

Koong, L. I., Baldwin, R. L., Ulyatt, M. J. \& Charlesworth, T. J. (1975). Iterative computation of metabolic fiux and stoichiometric parameters for alternate pathways in rumen fermentation. Computer Programs in Biomedicine 4, 209-213.

McDougall, E. I. (1948). Studies on ruminant saliva. I. The composition and output of sheep's saliva. Biochemical Journal 43, 99-106.

MacLeod, N. A. \& Ørskov, E. R. (1984). Absorption and utilization of volatile fatty acids in ruminants. Canadian Journal of Animal Science 64, Suppl., 354-355.

Masson, M. J. \& Phillipson, A. T. (1951). The absorption of acetate, propionate and butyrate from the rumen of sheep. Joumal of Physiology 113, 189-206.

Murphy, M. R., Baldwin, R. L. \& Koong, L. J. (1982). Estimation of stoichiometric parameters for rumen fermentation of roughage and concentrate diets. Journal of Animal Science 55, 41 [-421.

Oshio, S. \& Tahata, I. (1984). Absorption of dissociated volatile fatty acids through the rumen wall of sheep. Canadian Journal of Animal Science 64, Suppl., 167-168.

Pfander, W. H. \& Phillipson, A. T. (1953). The rates of absorption of acetic, propionic and $n$-butyric acids. Journal of Physiology 122, 102-110.

SAS Institute Inc. (1985). SAS User's Guide: Statistics, version 5 ed. Cary: SAS Institute Inc.

Snedecor, G. W. \& Cochran, W. G. (1967). Statistical Methods, 6th ed. Ames: Iowa State University Press.

Stevens, C. E. (1970). Fatty acid transport through the rumen epithelium. In Physiology of Digestion and Metabolism in the Ruminant, pp. 101-112 [A. T. Phillipson, E. F. Annison, D. G. Armstrong, C. C. Balch, R. S. Comline, R. N. Hardy, P. N. Hobson and R. D. Keynes, editors]. Newcastle-upon-Tyne: Oriel Press.

Sutherland. T. M. (1963). The metabolism of short chain fatty acids in the ruminant. In Progress in Nutrition and Allied Sciences, pp. 159-170 [D. P. Cuthbertson, editor]. Edinburgh: Oliver \& Boyd.

Sutton, J. D. (1985). Digestion and absorption of energy substrates in the lactating cow. Journal of Dairy Science 68, 3376-3393. 
Tamminga, S. \& Van Vuuren, A. M. (1988). Formation and utilization of end products of lignocellulose degradation in ruminants. Animal Feed Science and Technology 21, 141-159.

Thomas, P. C. \& Martin, P. A. (1988). The influence of nutrient balance on milk yield and composition. In Nutrition and Lactation in the Dairy Cow, pp. 97-118 [P. C. Garnsworthy, editor]. London: Butterworths.

Thorlacius, S. O. \& Lodge, G. A. (1973). Absorption of steam-volatile fatty acids from the rumen of the cow as influenced by diet, buffers and pH. Canadian Journal of Animal Science 53, 279-288.

Thornley, J. H. M. \& Johnson, I. R. (1990). Plant and Crop Modelling. Oxford: Clarendon Press.

Tsuda, T. (1956). Studies on the absorption from the rumen. II. Absorption of several organic substances from the miniature rumen of the goat. Tohoku Journal of Agricultural Research 7, 241-256.

Uden, P., Colluci, P. E. \& Van Soest, P. J. (1980). Investigation of chromium, cerium and cobalt as markers in digesta. Journal of the Science of Food and Agriculture 31, 625-632.

Von Engelhardt, W. \& Hauffe, R. (1975). Role of the omasum in absorption and secretion of water and electrolytes in sheep and goats. In Digestion and Metabolism in the Ruminant, pp. 216-230 [I. W. McDonald and A. C. I. Warner, editors]. Armidale: University of New England Publishing Unit.

Warner, A. C. I. \& Stacey, B. D. (1972). Water, sodium and potassium movements across the rumen wall of sheep. Quarterly Journal of Experimental Physiology 57, 103-119.

Weigand, E., Young, J. W. \& McGilliard, A. D. (1972). Extent of butyrate metabolism by bovine ruminoreticulum epithelium and the relationship to absorption rate. Journat of Dairy Science 55, 589-597. 